\title{
A Techno Economical Study on Wind Turbine Blade Waste as Replacement of Natural Coarse Aggregates in Concrete
}

\author{
Saket Sorathiya ${ }^{1}$, Prof. (Mrs.) Neha R. Patel ${ }^{2}$, Dr. Jayeshkumar Pitroda ${ }^{3}$ \\ ${ }^{1}$ Finalyear M. Tech. Student, Environmental Engineering, B.V.M. Engineering College, \\ V.V. Nagar, Gujarat, India \\ ${ }^{2}$ Associate Professor, Civil Engineering Department, B.V.M. Engineering College, \\ V.V. Nagar, Gujarat, India \\ ${ }^{3}$ AssistantProfessor, Civil Engineering Department, B.V.M. Engineering College, \\ V.V. Nagar, Gujarat, India
}

\begin{abstract}
During 1983-84 wind energy programs was commenced in India as 6th five yearly plans and in the last few years it has increased considerably. With the rapid wind energy industry growth, the question which has arises is how to deal with end-of-life turbines which has large amount of wind turbine blade waste. Wind turbine blades generally consist of reinforcement fibres, such as glass fibres or carbon fibres; a plastic polymer, such as polyester or epoxy; sandwich core materials such as polyvinyl chloride (PVC), PET or balsa wood; and bonded joints, coating (polyurethane), and lightning conductors. Currently waste of wind turbine is disposed on landfill, incinerated or recycled. Recycling potential of the waste is very limited and other two options are polluting environment in its own manner. The paper here presents utilization of WTBW (Wind Turbine Blade Waste) in concrete as a replacement material of natural aggregate. WTBW is replaced with Natural Coarse Aggregate in different proportions like 20\%, 40\%, 60\%, 80\%, and 100\%. In this paper detail discussion of compressive test and result is represented.
\end{abstract}

Keywords: Wind turbine blade waste, hazardous waste, environmental preservation, waste utilization, resource conservation, environmental pollution, hazardous waste recycle.

\section{INTRODUCTION}

Renewable energy sources are very important part of the sustainable development. With the increase of development \& industrialization need of energy also has increase. Use of non-conventional energy has been increase for the past few years and it is helpful for conserving current conventional energy resources. People are generating energy using wind for many decades. But, its implementation for generating large amount of energy was not there. Compare to other non-conventional energy industries wind turbine industry is very young.

Wind turbine industry is worldwide one of the fastest growing non-conventional industry for the past few years. Wind turbine blade is one important part of the whole wind turbine system. Material used for manufacturing wind turbine blade is reinforcement fibres, such as glass fibres or carbon fibres; a plastic polymer, such as polyester or epoxy; sandwich core materials such as polyvinyl chloride (PVC), PET or balsa wood; and bonded joints, coating (polyurethane), and lightning conductors.

Life of wind turbine blade is around 25-30 years. First generation of installed wind turbine blades are retiring now and creating mountainous problem for the wind turbine industries. Because of the material of wind turbine blade and size, it is very difficult to handle this waste. Currently industries are dealing with the waste by supplying it to cement industries and there the waste is incinerated. Environmentally it is not feasible solution and so for proper solution we try to utilize the waste in concrete as a replacement material of natural aggregate. The advancement in concrete technology can reduce the consumption of naturally available resources. There is urgent requirement to focus on recovery, reuse of natural resources and find other similar material. The use of the replacement materials reduces cost, savings in consumption of energy, arguably superior products, and reduces hazards in the environment. [5] [4] 


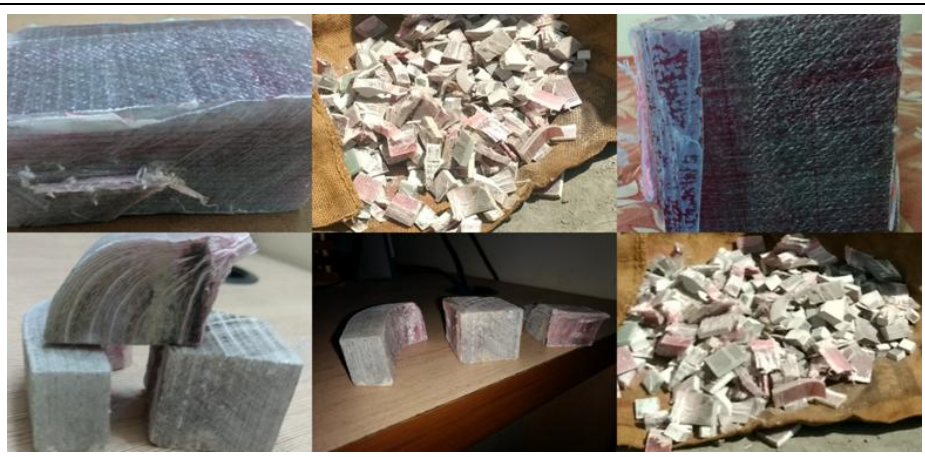

Figure1. Wind Turbine Blade Waste

(Source: Wind Turbine Industry, Halol)

Concrete is one of the most commonly used construction material. The raw materials from which it is prepared; cement and aggregates affect both the quality and cost of construction. Aggregates are usually cheaper than cement and constitute over $70 \%$ the volume of concrete. The availability and proximity of aggregate to the construction site also affect the cost of construction. As rapid construction and development is going on use of natural aggregate has also rapidly increased. As natural recourse is reducing ultimately it is affecting environment and creating imbalance. To address this situation attention has been shifted to low cost or waste material which can be used as building material. [6]

According to Saket $S$ et al. (2017) there is increase in generation of industrial and other type of waste and on other side utilization and reuse of waste in different construction application also has increased. Still there is lot of scope in the utilization of such waste in the different application of construction industry. [1]

\section{EXPERIMENTAL MATERIALS}

Following are the experimental materials for the research experimental work

\subsection{Cement}

Cement basically acts as a binding material that holds all the other components of the block. The cement available in the local market (OPC) Cement 53 grades Conforming to IS 8112: 2009 is used.

\subsection{Coarse Aggregate}

Natural Crushed Stone conforming to IS: 383 (1987) was employed. Coarse aggregate of size $10 \mathrm{~mm}$ down having the specific gravity of 2.84 and fineness modulus of 5.732 was applied.

\subsection{Fine Aggregate}

The natural river sand available in the local market is used as a fine aggregate. The fine and coarse aggregates shall consist of crushed or uncrushed materials, which apart from the grading requirements comply with IS 383:1970. The fine aggregate belongs to grading Zone II as per IS: 383-1970. Fineness Modulus of sand is 2.935 . The specific gravity of fine aggregate is 2.65 .

\subsection{Water}

The water shall be clean and free from deleterious matter. It shall meet the requirements stipulated in IS 456:2000.

\subsection{Wind Turbine Blade Waste (WTBW)}

The material for this project was collected from locally available distributors. Waste material required for this project which is WTBW is collected from wind turbine industry located near Vadodara. Waste material is recycled and the size of the waste material is reduced to $20-25 \mathrm{~mm}$ which is nearly same as Natural Aggregate.

\section{DESIGN MiX}

Design Mix of M30 Grade with Replacement of Natural Coarse Aggregate by Wind Turbine Blade Waste is done. As shown in Table 1 and same were used to prepare various batches of concrete for replacement of natural coarse aggregate by Wind Turbine Blade Waste. The design mix proportion is shown in Table 2. 

in Concrete

Waste material Wind Turbine Blade Waste is than replaced with Natural Coarse Aggregate in different proportions. We prepared six batches of M30 grade concrete consisting standard M30 grade concrete (A), 20\% replacement of NA (B1), 40\% replacement of NA (B2),60\% replacement of NA (B3),80\% replacement of NA (B4), $100 \%$ replacement of NA (B5).

Table1. Design Mix ofM30 Grade of Concrete (IS:10262:2009)

\begin{tabular}{|c|c|c|c|c|}
\hline Cement & F. A & C. A & WTBW & Water \\
\hline 435.73 & 695.82 & 1166.37 & 0 & 198.58 \\
\hline 1 & 1.59 & 2.67 & 0 & 0.45 \\
\hline
\end{tabular}

F. A. = Fine Aggregate, C. A. = Coarse Aggregate, WTBW = Wind Turbine Blade Waste

Table2. Replacement of Coarse Aggregate by WTBW in M30 Grade Concrete

\begin{tabular}{|c|c|c|c|c|c|c|c|}
\hline $\begin{array}{c}\text { Concrete } \\
\text { Mixes }\end{array}$ & $\begin{array}{c}\text { Coarse } \\
\text { Aggregate } \\
\text { Replacement } \\
\text { With WTBW }\end{array}$ & $\begin{array}{c}\text { Concrete } \\
\text { Quantity } \\
\left(\mathbf{m}^{\mathbf{3}}\right)\end{array}$ & $\begin{array}{c}\text { Cement } \\
(\mathbf{k g})\end{array}$ & $\begin{array}{c}\text { Water } \\
(\mathbf{L})\end{array}$ & $\begin{array}{c}\text { Coarse } \\
\text { Aggregate } \\
\text { (kg) }\end{array}$ & $\begin{array}{c}\text { Fine } \\
\text { Aggregate } \\
\text { (kg) }\end{array}$ & $\begin{array}{c}\text { WTBW } \\
\text { (kg) }\end{array}$ \\
\hline A & $0 \%$ & 1 & 425.73 & 191.58 & 1166.37 & 695.82 & 0.00 \\
\hline B1 & $20 \%$ & 1 & 425.73 & 191.58 & 933.09 & 695.82 & 233.27 \\
\hline B2 & $40 \%$ & 1 & 425.73 & 191.58 & 699.82 & 695.82 & 466.55 \\
\hline B3 & $60 \%$ & 1 & 425.73 & 191.58 & 466.55 & 695.82 & 699.82 \\
\hline B4 & $80 \%$ & 1 & 425.73 & 191.58 & 233.27 & 695.82 & 933.09 \\
\hline B5 & $100 \%$ & 1 & 425.73 & 191.58 & 0.00 & 695.82 & 1166.37 \\
\hline
\end{tabular}

WTBW $=$ Wind Turbine Blade Waste

Where, A is Standard M30 grade concrete, B1 to B5 is Wind Turbine Blade Waste Concrete in different proportion.

\section{Experimental Methodology}

\subsection{Testing Methodology}

The concrete was batched and mixed according to IS 516:1959.The cube moulds were cleaned and oiled before each casting. The coarse aggregate was the mixture of Natural Aggregate (NA) and WTBW in the proportion of by $0 \%(\mathrm{~A}), 20 \%(\mathrm{~B} 1), 40 \%(\mathrm{~B} 2), 60 \%(\mathrm{~B} 3), 80 \%(\mathrm{~B} 4), 100 \%(\mathrm{~B} 5)$. Nine concrete cubes of $150 \mathrm{~mm}$ were produced for each mix. Demoulding of the cubes was done between 18 hours to 24 hours after casting. The hardened cubes were transferred immediately into the curing tank at room temperature. The cubes were removed at the end of 7, 14 and 28 days from the curing tank and air dried for about 3 hours before testing. The results of the compression tests at 7, 14, 28 days are given in Table 3 and Figure 3.

\subsection{Compressive Strength Test Results [IS 516:1959]}

Compressive strength tests were performed on compression testing machine using concrete cube samples. Three samples per batch were tested with the average strength values reported in this paper. The cubes have been stored in $24 \pm 4 \mathrm{~h}$ in water maintained at a temperature of $20 \pm 5^{\circ} \mathrm{C}$. The bearing plates of the testing machine shall be wiped clean. The specimens are aligned with those of the bearing plates. The load would be applied without shock and increased continuously at a rate of $15 \pm 3$ $\mathrm{N} / \mathrm{mm}^{2} / \mathrm{min}$ until no greater load can be sustained by the specimen or delaminating occurs. The maximum loads applied to the specimen were noted.Figure 2 shows the setup of compressive strength testing machine. The compressive strength results are compiled in Table3.

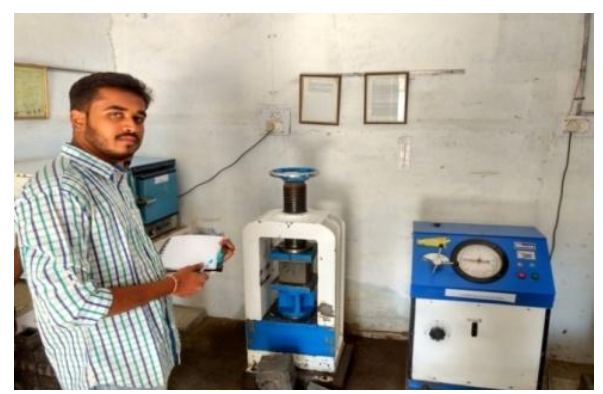

Figure2. Setup of Compression compressive strength testing machine 
Saket Sorathiya et al.

Table3. Comparative Experimental Results of Compressive Strength Test for M30 Mixes: Standard Concrete and Concrete with Replacement of WTBW in Different Proportions

\begin{tabular}{|c|c|c|c|c|c|c|}
\hline \multirow[t]{2}{*}{$\begin{array}{l}\text { Concrete } \\
\text { Mixes }\end{array}$} & \multicolumn{3}{|c|}{$\begin{array}{c}\text { Average } \\
\text { Compressive Strength }\left(\mathrm{N} / \mathrm{mm}^{2}\right)\end{array}$} & \multicolumn{3}{|c|}{ \% Change in Compressive Strength } \\
\hline & 7 Days & 14 Days & 28 Days & 7 Days & 14 Days & 28 Days \\
\hline \multicolumn{7}{|c|}{ Standard Concrete Mix M30 } \\
\hline $\mathbf{A}$ & 15.70 & 24.44 & 30.81 & 0 & 0 & 0 \\
\hline \multicolumn{7}{|c|}{ M30 Grade Concrete with Replacement of WTBW in Different Proportions } \\
\hline B1 $(20 \%)$ & 24.59 & 32.30 & 34.96 & 56.62 & 32.16 & 13.47 \\
\hline B2 $(40 \%)$ & 20.44 & 28.89 & 32.89 & 30.19 & 18.21 & 6.75 \\
\hline B3 (60\%) & 16.30 & 27.11 & 31.11 & 3.82 & 10.92 & 0.97 \\
\hline B4 $(80 \%)$ & 21.48 & 31.41 & 34.81 & 36.82 & 28.52 & 12.98 \\
\hline B5 (100\%) & 25.04 & 34.67 & 38.22 & 59.49 & 41.86 & 24.05 \\
\hline
\end{tabular}

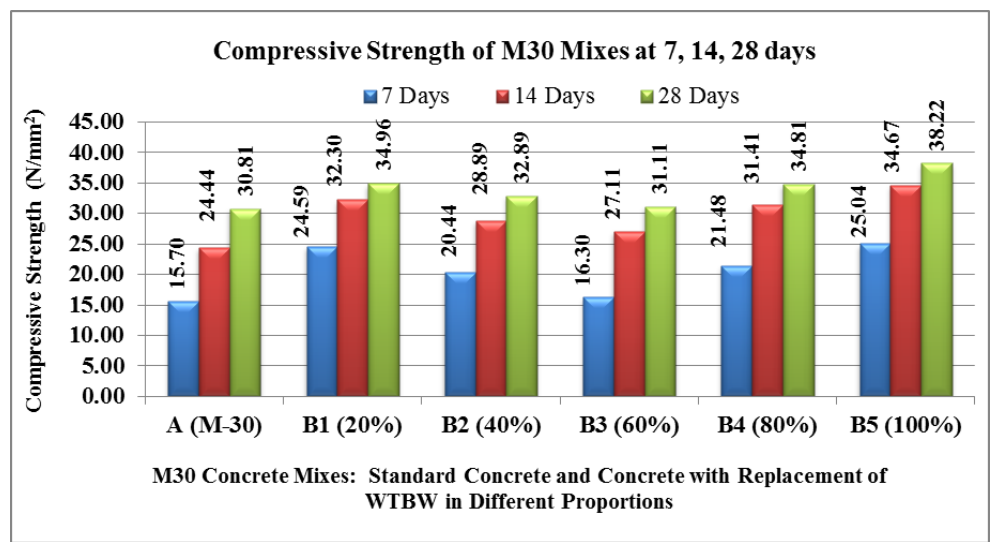

Figure3. Compressive Strength of M30 Mixes: Standard Concrete and Concrete with Replacement of WTBW in Different Proportionate 7, 14, 28 Days

The results of compressive strength were presented in Table 3 . The test was carried out to obtain compressive strength of concrete at the age of 7, 14 and 28 days. The cubes were tested using compression testing machine of capacity $2000 \mathrm{KN}$. From the figure 3 the compressive strength is highest for 28 days when replacing $100 \%$ of coarse aggregate by WTBW in concrete.

For 7 day test compressive test was done and from Table 3. It can be seen that $\%$ change in compressive strength for B1 compare to A is $56.62 \%$. For B2 and B3 it constantly reduces but for B4 and B5 compressive strength again increases up to $\mathbf{5 9 . 4 9 \%}$.

For 14 day test compressive test was done and from Table 3. It can be seen that $\%$ change in compressive strength for B1compare to A is $32.16 \%$. For B2 and B3 it constantly reduces but for B4 and B5 compressive strength again increases up to $\mathbf{4 1 . 8 6 \%}$.

For 28 day test compressive test was done and from Table 3. It can be seen that $\%$ change in compressive strength for B1compare to A is $13.47 \%$. For B2 and B3 it constantly reduces but for B4 and B5 compressive strength again increases up to $\mathbf{2 4 . 0 5 \%}$.

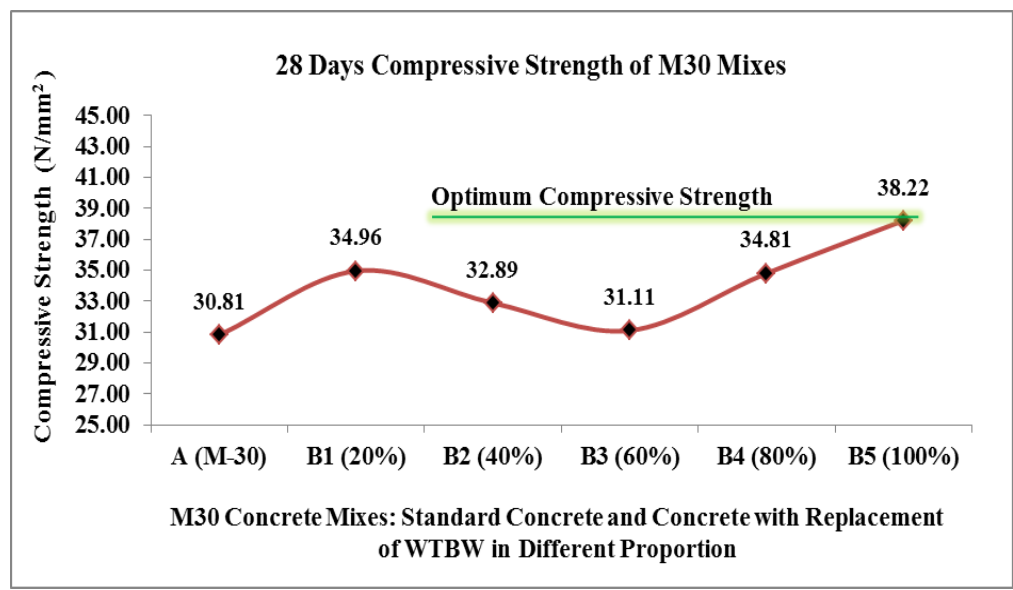

Figure4. Compressive Strength of M30 Mixes: Standard Concrete and Concrete with Replacement of WTBW in Different Proportion at 28 Days 
A Techno Economical Study on Wind Turbine Blade Waste as Replacement of Natural Coarse Aggregates in Concrete

From above figure 3 and 4, it can be said that compressive strength of the M30 grade of concrete mixes increased with increase in days. Also compressive strength increases with replacement of WTBW $20 \%$ than decreases for $40 \%$ and $60 \%$ than again increase with replacement of WTBW up to $100 \%$, compressive strength decreases for $40 \%$ and $60 \%$ but it was higher than the standard concrete mixes. So optimum WTBW replacement for maximum compressive strength was 100\%. For 100\% B5 mix shows $\mathbf{2 4 . 0 5 \%}$ increase in compressive strength compare to standard A mix.

\section{ECONOMIC ANALYSIS}

The addition of WTBW increases strength of concrete. Apart of this there are other benefits of WTBW replacement. Firstly it provides an environmentally consistent way of WTBW disposal. Secondly in overall it reduces the cost of concrete. Replacement of WTBW shall reduce the quantity of natural coarse aggregate required and hence the overall cost. The effect on overall cost of the concrete can be analyzed by taking an example. In the subsequent Section, concrete road pavement is designed using various proportion of WTBW and their cost is estimated.

\subsection{Rate of Basic Materials}

The prevailing market rate gives cost on materials per $\mathrm{kg}$ as given Table 4. The Table 5 shows Total Cost of M30 Grade Concrete Mixes for $1 \mathrm{~m}^{3}$ with WTBW in Different Proportions (Mixes B1, B2, B3, B4, and B5) and figure 5 shows graphically Cost of Concrete for M30 Grade Mixes: Standard Concrete and Concrete with WTBW in Different Proportions.

Table4. Costs of Materials

\begin{tabular}{|c|c|c|}
\hline Sr.No. & Materials & Rate (Rs/Kg) \\
\hline 1 & Cement & 5.4 \\
\hline 2 & Water & 0 \\
\hline 3 & Fine Aggregate & 0.6 \\
\hline 4 & Coarse aggregate & 0.65 \\
\hline 5 & WTBW & 0.20 \\
\hline
\end{tabular}

Table5. Total Cost of M30 Grade Concrete Mixes for $1 \mathrm{~m}^{3}$ with WTBW in Different Proportions (Mixes B1, B2, $B 3, B 4$, and B5)

\begin{tabular}{|c|c|c|c|c|c|c|c|}
\hline \multirow{2}{*}{$\begin{array}{l}\text { Concrete } \\
\text { Mixes }\end{array}$} & \multirow{2}{*}{$\begin{array}{l}\text { \% Replacement } \\
\text { of WTBW }\end{array}$} & \multicolumn{4}{|c|}{ Designed Material for Concrete $\left(\mathrm{kg} / \mathrm{m}^{3}\right)$} & \multirow{2}{*}{$\begin{array}{l}\text { Total } \\
\text { Cost } \\
(\text { Rs) }\end{array}$} & \multirow{2}{*}{$\begin{array}{c}\% \\
\text { Change } \\
\text { in Cost }\end{array}$} \\
\hline & & Cement & F.A & C.A & WTBW & & \\
\hline $\mathbf{A}$ & $\mathbf{0}$ & 425.73 & 695.82 & 1166.37 & 0.00 & 3476 & $\mathbf{0}$ \\
\hline B1 & 20 & 425.73 & 695.82 & 933.09 & 233.27 & 3370 & -3.05 \\
\hline $\mathbf{B 2}$ & 40 & 425.73 & 695.82 & 699.82 & 466.55 & 3265 & -6.07 \\
\hline B3 & 60 & 425.73 & 695.82 & 466.55 & 699.82 & 3160 & -9.09 \\
\hline B4 & 80 & 425.73 & 695.82 & 233.27 & 933.09 & 2870 & -17.43 \\
\hline B5 & 100 & 425.73 & 695.82 & 0.00 & 1166.37 & 2715 & -21.89 \\
\hline
\end{tabular}

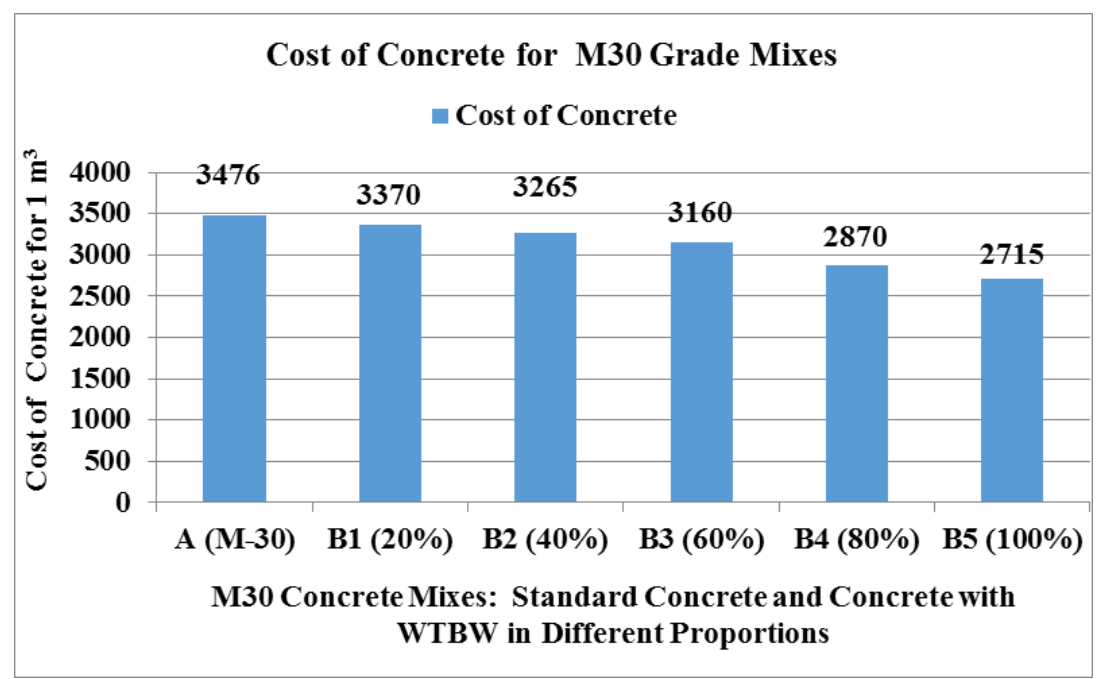

Figure5. Cost of Concrete for M30 Grade Mixes: Standard Concrete and Concrete with WTBW in Different Proportions 
From above figure 5, it can be said that concrete mixes (M30) with replacement of NA by WTBW have lower rates for $1 \mathrm{~m} 3$ concrete with compared to standard A (M30) concrete mix. Rate of concrete decreases with increases of WTBW replacement in the concrete. By using WTBW we can reduce cost of per $\mathrm{m}^{3}$ concrete by $21.89 \%$ compare to slandered concrete.

\section{Conclusions}

From the above experimental test, following conclusion is drawn:

a) Compressive strength of concrete was increasing by replacement of WTBW in different proportion for M30 grade of concrete as compared to standard concrete.

b) Results shows that optimum WTBW Replacement for highest compressive strength is $100 \%$, and it also indicate that compressive strength increases and reach maximum for replacement of NA with WTBW $100 \%$.

c) B5 batch of M30 grade made with $100 \%$ replacement shows $\mathbf{2 4 . 0 5} \%$ increase in compressive strength as compared to A mix (Standard M30).

d) Rates of concrete decreases with increases of WTBW replacement in the concrete. By using WTBW we can reduce cost of per $\mathrm{m}^{3}$ concrete by $\mathbf{2 1 . 8 9 \%}$ compare to slandered concrete.

\section{ACKNOWLEDGEMENT}

The Authors thankfully acknowledge to Dr. C. L. Patel, Chairman, Charutar Vidya Mandal, and Er. V. M. Patel, Hon. Jt. Secretary, Charutar Vidya Mandal, Prof. (Dr.) Indrajit Patel, Principal, B.V.M. Engineering College, Vallabh Vidyanagar, Gujarat, India for their motivations and infrastructural support to carry out this research.

\section{REFERENCES}

[1] Saket Sorathiya, Dr. Jayesh Pitroda, Mrs. Neha Patel "Feasibility Report on Recycle and Reuse of Wind Turbine Blade Waste: A Review" International Conference on Research and Innovations in Science, Engineering \& Technology, 17-19 February, 2017, ISBN : 978-93-84339-38-8.

[2] Deepak Sangroya, Dr. Jogendra Kumar Nayak, "Development of Wind Energy in India", International Journal of Renewable Energy Research, Deepak Sangroya et al., Vol.5, No.1, 2015.

[3] "Disused Rotor Blades Can Now Be Utilized in Cement Production." Holcim. Holcim 2015, n.d Web. 04 Dec. 2015. <http://www.holcim.com/referenceprojects/disused-rotor-blades-can-now-beutilized-in-cement-production.html>.

[4] Gino Omar Calder'on Vizcarra; Michéle Dal ToéCasagrande; and Laura Maria Goretti da Motta, Applicability of Municipal Solid Waste Incineration Ash on Base Layers of Pavements, 10.1061/(ASCE)MT.1943-5533.0000903. @ 2014 American Society of Civil Engineers.

[5] Hofmeister, Michael. Recycling Turbine Blade Composites: Concrete Aggregate and Reinforcement. Tech. N.p.: n.p., 2012.

[6] N.S.Apebo, M.B. Iorwua,J.C. Agunwamba, "Comparative Analysis of the Compressive Strength of Concrete with Gravel and Crushed over Burnt Bricks as Coarse Aggregates", Nigerian Journal of Technology (NIJOTECH), Vol. 32, No. 1, March, 2013, pp. 7-12.

[7] Yue Huang, Roger N. Bird, Oliver Heidrich, "A review of the use of recycled solid waste materials in asphalt pavements", Resources, Conservation and Recycling 52 (2007) 58-73. 


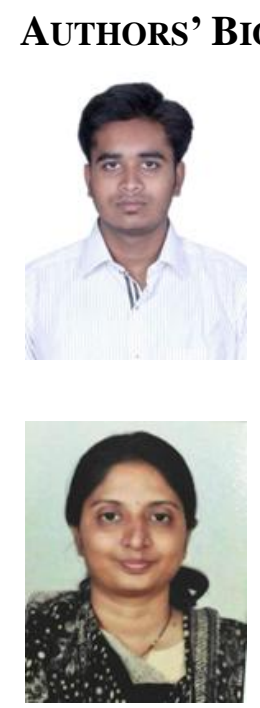

Prof. Neha R Patel, received her Bachelor of Engineering degree in Civil Engineering from the REC (SVNIT) Surat, South Gujarat University in 1993. In 2002 she received her Master's Degree in Civil (Environmental) Engineering from REC (SVNIT) Surat, South Gujarat University. She joined Birla Vishwakarma Mahavidyalaya Engineering College as a faculty in 2002, where she is Associate Professor of Civil Engineering Department with a total experience of 14 Years in the field of Research, Designing and education. She is guiding M.E. (Environmental Engineering) Thesis work in the field of Civil/ Environmental Engineering. She has published many papers in National/ International Conferences and International Journals.

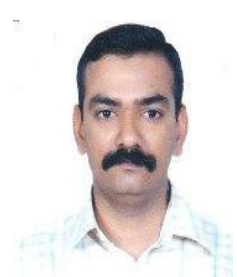

Dr. Jayeshkumar R Pitroda, received his bachelor of engineering degree in Civil Engineering from Birla Vishwakarma Mahavidyalaya Engineering College, Sardar Patel University in 2000. In 2009 he received his master's degree in Construction Engineering and Management from Birla Vishwakarma Mahavidyalaya Sardar Patel University. In 2015 he received his Doctor of philosophy (Ph.D.) degree in Civil Engineering from Sardar Patel University. He joined Birla Vishwakarma Mahavidyalaya Engineering College as a faculty in 2009, where he is Assistant Professor of Civil Engineering Department with a total experience of 16 years in the field of research, designing and education. He is guiding M.E. (Construction Engineering and Management) thesis work in the field of Civil / Construction Engineering. He has published many papers in National / International Conferences and International Journals. He has published seven Research Books in the field of Civil Engineering, Rural Road Construction, National Highways Construction, Utilization of Industrial Waste, Fly Ash Bricks, Construction Engineering and Management, Eco-friendly Construction. 